\title{
Natural history of immunoglobulin E-mediated cow's milk allergy in a population of Argentine children
}

\author{
Natalia A. Petriz, ${ }^{a}$ M.D., Claudio A. S. Parisi M.D., ${ }^{a, e}$ Julio N. Busaniche, M.D., ${ }^{b}$ \\ Patricia Evangelista, M.D. ${ }^{c}$ Romina Mehaudy, M.D. ${ }^{d}$ and Marina Orsi, M.D. ${ }^{d}$
}

\begin{abstract}
Introduction. Cow's milk proteinallergy is themost common allergy in pediatrics. Immunoglobulin E (IgE)-mediated cow's milk allergy poses a higher risk for life and a worse prognosis.

Objectives. To describe the course of IgEmediated cow's milk protein allergy and risk factors associated with disease persistence.

Patients and methods. This was a descriptive, retrospective study conducted in patients seen at the Division of Pediatric Allergy of Hospital Italiano between June 2006 and June 2012 who had been diagnosed with IgE-mediated cow's milk allergy.

Results. Out of the 72 patients with IgEmediated cow's milk allergy, 39 (54\%) were boys. Patients' average age at the time of diagnosis was $5.19 \pm 3.7$ months old; the most common symptoms were urticaria and vomiting. Rhinitis and asthma were the most commonly observed concomitant atopic diseases. In the study period, $54.5 \%$ of patients developed tolerance at an average age of 32 months old. An 8-mm papule in the skin prick test and casein sensitization were associated with disease persistence.

Conclusion. Overall, $54.5 \%$ of patients developed tolerance at 32 months old. A significant association was observed between papule size at the time of diagnosis and casein sensitization and disease persistence.

Key words: allergy, milk, immunoglobulin E, natural history.
\end{abstract}

http:/ / dx.doi.org/10.5546/ aap.2017.eng.331

To cite: Petriz NA, Parisi CAS, Busaniche JN, et al. Natural history of immunoglobulin E-mediated cow's milk allergy in a population of Argentine children. Arch Argent Pediatr 2017;115(4):331-335.

\section{INTRODUCTION}

Cow's milk protein allergy (CMPA) is defined as a reproducible adverse reaction of immune nature induced by cow's milk protein. It may be classified into immunoglobulin E (IgE)-mediated, non-IgE-mediated or mixed allergy, depending on the pathophysiological mechanism involved. ${ }^{1}$
CMPA is the most common food allergy in pediatrics. CMPA prevalence among children younger than 2 years old has been $1.8-7.5 \%$ as per different series. This broad prevalence range is the result of different diagnostic criteria, genetic and environmental factors. Such multiple factors interacting with one another lead to an increased prevalence. ${ }^{1,2}$

Most studies have shown that tolerance to cow's milk in the case of IgE-mediated allergy occurs around 3 years old. A study conducted in Argentina described that, in 55 children, tolerance developed around 2 years old. ${ }^{3}$ Other studies found less optimistic results in relation to IgE-mediated CMPA, with disease persistence until 8.6 years old. ${ }^{4}$

The objective of this study was to describe the natural history of IgEmediated CMPA and establish if there were risk factors associated with disease persistence.

\section{PATIENTS AND METHOD}

Design: Descriptive, retrospective study. The study was approved by the Institutional Ethics Committee.

Population: Patients diagnosed with IgE-mediated CMPA who sought care at the Division of Pediatric Allergy of Hospital Italiano de Buenos Aires between June 2006 and June 2012. Among patients seen here during the study period, a group had participated in a study that has already been published and had a double blind placebo controlled food challenge test. ${ }^{3}$ Patients were included in this study if they had not been subjected to that test. 
Inclusion criterion: patients with IgE-mediated CMPA.

\section{Outcome measures}

- Age at diagnosis in months old.

- Sex.

- Clinical signs at the time of diagnosis: Presence of anaphylaxis, angioedema, bronchospasm, respiratory distress, abdominal cramps, dermatitis, cardiorespiratory arrest, gastroesophageal reflux, rhinoconjuntivitis, constipation, hematochezia, diarrhea, steatorrhea, failure to thrive, urticaria and/or vomiting.

- Personal history of allergy: Patients were considered to have a positive history if they reported asthma, rhinitis, atopic dermatitis, egg allergy. This outcome measure was dichotomized into positive and negative history.

- Recommended feeding when diagnosis is suspected: Breast milk, amino-acid based formula, extensively hydrolyzed formula, partially hydrolyzed formula.

- Specific IgE titer: Specific IgE serum levels for cow's milk protein were obtained from serum samples. Measurement was made by means of an enzyme-linked immunosorbent assay (ELISA) or a Capture Assay Radim Liquid Allergens (CARLA).

- Skin prick/puncture test with immediate reading (SPT): The same person performed all skin tests on the interscapular region. The following allergenic extracts were used: milk (Alergo Pharma, Argentina), alpha-lactalbumin, betalactoglobulin, casein (Q Alergia, Argentina), and fresh skim milk. Metal lancets were used for the prick test (DIATER Laboratorios). The area was cleaned with a cotton swab dipped in alcohol; a marker was used to point out the place where the extracts ( 1 drop) or milk (1 drop) were applied, at a distance of more than $2 \mathrm{~cm}$ from one another. A superficial puncture was made on each substance. A positive control (histamine, $10 \mathrm{mg} / \mathrm{mL}$ ) and a negative control (glycerinated saline solution) were also used. A millimeter graduated ruler was used to read the test 20 minutes later, and the measurement corresponding to the average papule diameter was reported in millimeters.

\section{Definitions}

- IgE-mediated CMPA: The diagnosis of IgEmediated CMPA was based on medical history (immediate allergy symptoms related to cow's milk protein intake), together with the SPT and ELISA results to establish the presence of specific IgE.

- Increased specific IgE: Value above $0.35 \mathrm{IU} / \mathrm{mL}$.

- Positive SPT: Diameter equal to or higher than $3 \mathrm{~mm}$ from the negative control.

- Controlled food challenge (CFC) test: An open food challenge test was done in all infants with a negative SPT and negative specific IgE to assess tolerance.

For the test, milk was administered progressively with a logarithmic volume increase every 20 minutes accompanied by a physical exam and vital signs monitoring to establish the presence of symptoms, as indicated in the Diagnosis and Rationale for Action Against Cow's Milk Allergy (DRACMA) guidelines. ${ }^{5}$ The test was considered positive if the patient had immediate hypersensitivity symptoms at any time after procedure initiation, or negative if the patient showed food tolerance.

All tests were done in the hospital by specialized health care staff under strict medical surveillance and using an adequate technique. ${ }^{5}$

- Tolerance: Tolerance was defined as the absence of symptoms following contact with the allergen. To confirm tolerance, CFC tests were done; tolerant individuals were those with a negative result. This was considered the time of tolerance acquisition.

- Patient follow-up: Follow-up was provided every 3-6 months, at the physician's discretion, by making an SPT with milk and milk protein and/or an ELISA test for specific IgE.

\section{Statistical analysis}

Data were stored in magnetic format (Excel), and data consistency and independent outcome measure distribution were assessed.

The SPSS statistical software was used. Outcome measures were described using central tendency and dispersion estimates based on measurements, and results were described as means and standard deviations.

Differences in proportions between tolerant and intolerant patients were analyzed using the $\chi^{2}$ test for quantitative outcome measures and Student's t test for continuous ones.

The Kaplan-Meier test was used to assess the duration of disease and the difference between tolerant and intolerant patients.

A value of $p<0.05$ was considered statistically significant. 


\section{RESULTS}

Based on the review of medical records, out of 116 patients with CMPA who did not participate in the previous study because they did not agree to undergo milk challenge, 72 patients with IgE-mediated CMPA were selected. Among these, 6 failed to return for their appointment, so 66 patients were included in this study; 39 (54\%) were boys.

The population's median age at the time of their first symptom was 5 months old, with a range of 1 to 24 months old (Table 1).

The most common symptom for consultation was urticaria $(54.2 \%)$, followed by immediate vomiting (30.6\%) (Figure 1). These clinical manifestations occurred once modified milk or dairy products were introduced in $89 \%$ of patients, and while breastfeeding in $11 \%$.

In relation to the formulas recommended once CMPA was suspected, $30 \%$ of patients received extensively hydrolyzed formula with cow's milk protein; $25 \%$, soy milk; $16.7 \%$, breast milk; and $15 \%$, amino acid-based formula.

Out of the 66 patients being followed-up, 36 children $(54.5 \%)$ tolerated food and $30(45.5 \%)$ continued with specific $\operatorname{IgE}$ as measured by any of the two methods used in this study.

Concomitant diseases were observed in 59.7\% of children; the most common were asthma, eczema, and egg allergy.

In relation to diagnostic tests, the SPT was positive in $84.7 \%$ of patients. The ELISA test was done in $91.6 \%$ of patients and was positive in $68.2 \%$.
Papules with a diameter larger than $8 \mathrm{~mm}$ in the SPT and casein sensitization at the time of diagnosis were associated with disease persistence $(p=0.01)$.

No correlation was found between the specific serum $\operatorname{IgE}$ and the total $\operatorname{IgE}$ at the time of diagnosis and tolerance acquisition.

The average age of children at the time of the negative CFC test was $31.6 \pm 18.7$ months old, and that of those who remained sensitive was $62.2 \pm 37.3$ months old.

The average time between CMPA diagnosis by SPT and CMPA resolution (negative CFC test) was $41.2 \pm 31.1$ months old (Table 1).

\section{DISCUSSION}

In our population of children with IgEmediated CMPA, tolerance acquisition occurred at a slightly older age than that observed in the study conducted by Bozzola et al., where spontaneous resolution occurred at an average of 23.14 months old. Such difference may be because of the diagnostic methodology used and the patient population, which included all CMPA subtypes (IgE-mediated, cell-mediated, and mixed mechanisms). In other Nordic studies, such as the one conducted by Skripak et al., ${ }^{4}$ the percentage of resolution was less optimistic: $42 \%$ at 8 years old. A possible explanation may be that patient follow-up may be biased by the health care facility. Tertiary care or national referral hospitals usually care for a more complex population with a worse clinical course.

TABLE 1. Study population information

\begin{tabular}{|c|c|c|c|}
\hline Outcome measure & All (66) & Tolerant children (36) & Intolerant children (30) \\
\hline Age at the time of diagnosis in months old; median (range) & $5(1$ to 24$)$ & $5(1$ to 24$)$ & $6(1$ to 18$)$ \\
\hline CMA duration in months; mean \pm standard deviation & $41.1 \pm 31.1$ & $28.0 \pm 17.0$ & $56.9 \pm 36.7$ \\
\hline CMA duration in months; median (range) & 30 (3 to 143$)$ & 25 (3 to 98$)$ & 40.5 (14 to 143$)$ \\
\hline Male sex; \% (n) & $50.0(33)$ & $44.4(16)$ & $56.6(17)$ \\
\hline $\begin{array}{l}\text { Baseline signs/symptoms (n): } \\
\text { Urticaria } \\
\text { Vomiting } \\
\text { Hematochezia } \\
\text { Diarrhea }\end{array}$ & $\begin{array}{c}53.0 \%(35) \\
30.3 \%(20) \\
9.0 \%(6) \\
16.6 \%(11)\end{array}$ & $\begin{array}{l}58.3 \%(21) \\
27.8 \%(10) \\
8.3 \%(3) \\
13.9 \%(5)\end{array}$ & $\begin{array}{l}46.6 \%(14) \\
33.3 \%(10) \\
10.0 \%(3) \\
20.0 \%(6)\end{array}$ \\
\hline $\begin{array}{l}\text { Concomitant conditions (n): } \\
\text { Asthma } \\
\text { Rhinitis } \\
\text { Other allergies }\end{array}$ & $\begin{array}{c}28.7 \%(19) \\
6.0 \%(4) \\
28.7 \%(19)\end{array}$ & $\begin{array}{c}19.4 \%(7) \\
0.0 \%(0) \\
25.0 \%(9)\end{array}$ & $\begin{array}{c}38.7 \%(12) \\
12.9 \%(4) \\
35.5 \%(10)\end{array}$ \\
\hline Positive skin prick test $(\mathrm{n})$ & $84.4 \%(56)$ & $75.0 \%(27)$ & $96.8 \%(29)$ \\
\hline $\operatorname{RAST}+(\mathrm{n})$ & $60.6 \%(40)$ & $55.5 \%(20)$ & $77.8 \%(20)$ \\
\hline
\end{tabular}

CMA: cow's milk allergy; RAST: radioallergosorbent test. 
The variation in the regions where the studies were done may have come into play in terms of cultural eating habits (breastfeeding, modified formula introduction, semi-solid food introduction, cooking techniques), as well as other environmental factors (exposure and sensitization to aeroallergens, infections, etc.), ${ }^{6-8}$ genetic and gut microbiome differences. ${ }^{9}$

As per international guidelines, the double blind placebo controlled food challenge test is the gold standard for the diagnosis of food allergies. The fact that this test was not done in our patients may be a weakness of this study. However, this type of procedure poses certain risks for an anaphylactic reaction. As per the DRACMA guidelines for the diagnosis and treatment of cow's milk allergy, ${ }^{5}$ patients with a high pretest probability based on their clinical history $(>80 \%)$, positive SPT (papule $>3 \mathrm{~mm}$ ) and positive ELISA test $(>0.35 \mathrm{IU} / \mathrm{mL})$, the risk of being falsely classified as allergic is $1 \% .{ }^{5}$

In addition, it is possible that some patients may have acquired tolerance before showing up negative in the specific IgE test, thus overestimating disease persistence.

Papule size in the SPT, larger than $8 \mathrm{~mm}$ in our study, resulted in a factor associated with cow's milk allergy persistence, as in other previously published studies. ${ }^{6,10-12}$
The association between CMPA persistence and casein sensitization observed in our study was also seen in previous studies. ${ }^{13}$

The specific IgE titer for cow's milk was not a factor associated with disease persistence (data were similar to those published by Fiocchi et al.). ${ }^{6}$ On the contrary, such correlation was observed in other studies. . $^{40,11,14}$ This may be because a different ELISA method was used in our study.

Also, $11 \%$ of patients with CMPA symptoms were breastfed, a much higher prevalence than that observed in other studies, where allergic reactions to breast milk were seen in $0.5 \%$ of cases. $^{15}$

\section{CONCLUSION}

In the studied population, cow's milk tolerance was observed at 32 months old in $54.5 \%$ of patients. Casein sensitization and papules larger than $8 \mathrm{~mm}$ in the SPT were associated with disease persistence.

\section{Acknowledgments}

The authors would like to thank Alejandro Fabián Álvarez, nurse, for his valuable collaboration.

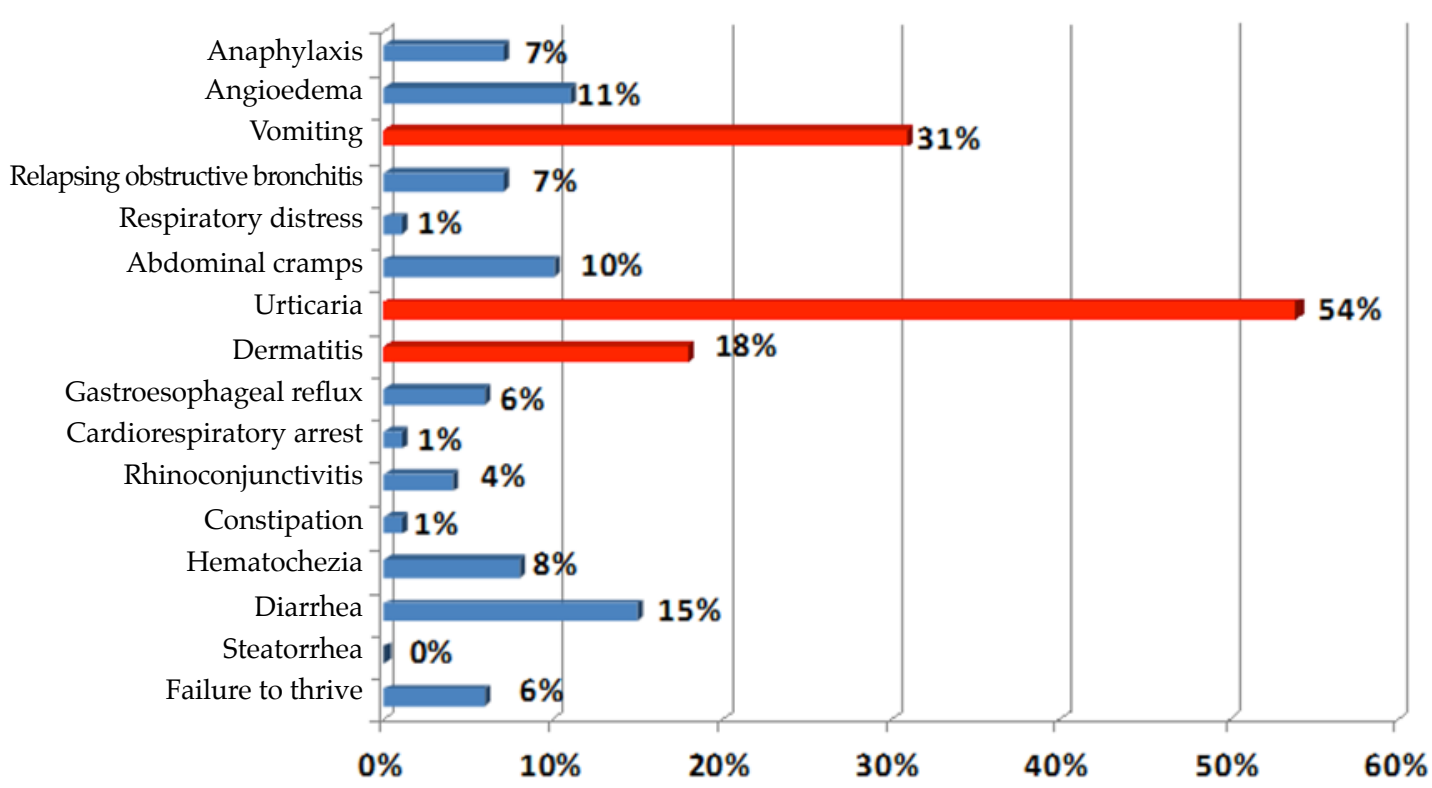




\section{REFERENCES}

1. Boyce JA, Assa `ad A, Burks AW, et al. Guidelines for diagnosis and management of food allergy in the United States: report of the NIAID-sponsored expert panel.J Allergy Clin Immunol 2010;126(6 Suppl):S1-58.

2. Orsi M, Fernández A, Follett F, et al. Alergia a la proteína de la leche de vaca. Propuesta de guía para el manejo de los niños con alergia a la proteína de la leche de vaca. Arch Argent Pediatr 2009;107(5):459-70.

3. Bozzola M, Marchetti P, Cosentino M, et al. Alergia a la proteína de leche de vaca. Evaluación de su resolución espontánea por medio de desafíos doble ciego placebo controlados. Arch Alerg Inmunol Clin 2015;46(2):44-8.

4. Skripak JM, Matsui EC, Mudd K, et al. The natural history of IgE-mediated cow`s milk allergy. J Allergy Clin Immunol 2007;120(5):1172-7.

5. Fiocchi A, Brozek J, Schünemann, et al. World Allergy Organization (WAO) Diagnosis and Rationale for Action against Cow $\square$ s Milk Allergy (DRACMA) Guidelines. World Allergy Organ J 2010;3(4):57-161.

6. Fiocchi A, Terracciano L, Bouygue GR, et al. Incremental prognostic factors associated with cow`s milk allergy outcomes in infant and child referrals: the Milan Cow`s Milk Allergy Cohort study. Ann Allergy AshtmaImmunol 2008;101(2):166-73.

7. Host A, Halken S, Jacobsen HP, et al. Clinical Course of cow`s milk protein allergy / intolerance and atopic diseases in childhood. Pediatr Allergy Immunol 2002;13(Suppl15):23-8.

8. Saarinen KM, Pelkonen AS, Mäkelä MJ, et al. Clinical course and prognosis of cow`s milk allergy are dependent on milk-specific IgE status. J Allergy Clin Immunol 2005;116(4):869-75.

9. Luyt D, Ball H, Makwana N, et al. BSACI guideline for the diagnosis and management of cow's milk allergy. Clin Exp Allergy 2014;44(5):642-72.

10. Vanto T, HelppilaS, Juntunen-Backman K, et al. Prediction of development of tolerance to milk in children with cow`s milk hypersensitivity. J Pediatr 2004;144(2):218-22.

11. Wood RA, SichererSH, Vickery BP, et al. The natural history of milk allergy in an observational cohort. J Allergy Clin Immunol 2013;131(3):805-12.

12. Elizur A, Rajuan N, Goldberg MR, et al. Natural course and risk factors for persistence of IgE-mediated cow`s milk allergy. J Pediatr 2012;161()3):482-7.

13. García-Ara MC, Boyano-Martínez MT, Díaz Pena JM, et al. Cow`s milk-specific inmunoglobulin E levels as predictors of clinical reactivity in the follow-up of the cow`s milk allergy infants. Clin Exp Allergy 2004;34(6):866-70.

14. Ahrens B, Lopes de Olivera LC, Grabennenrich L, et al. Individual cow`s milk allergens as prognostic markers for tolerance development? Clin Exp Allergy 2012;42(11): 1630-7.

15. Høst A. Frequency of cow $\square$ s milk allergy in childhood. Ann Allergy Asthma Immunol 2002;89(Suppl 1):33-7. 